\title{
The Analysis on the Mechanism of the Disabled Labor Market and the Macro-Control Countermeasures
}

\author{
Manlin Kang \\ Jinan University, Jinan, China \\ Email:2232432861@qq.com
}

How to cite this paper: Kang, M.L. (2017) The Analysis on the Mechanism of the Disabled Labor Market and the Macro-Control Countermeasures. Journal of Human Resource and Sustainability Studies, 5, 125-133.

https://doi.org/10.4236/jhrss.2017.52012

Received: March 7, 2017

Accepted: April 8, 2017

Published: April 11, 2017

Copyright $\odot 2017$ by author and Scientific Research Publishing Inc. This work is licensed under the Creative Commons Attribution International License (CC BY 4.0).

http://creativecommons.org/licenses/by/4.0/

\begin{abstract}
This paper describes the unbalanced mechanism of disabled labor market from the perspective of supply and demand matching. There are two stages which significantly compose supply and demand, shown as base layer and communication layer. The base layer is the premise of both supply side and demand side to participate in market communication, mainly determined by subjective factors. Moreover, the object of the communication layer is the output of the base layer. Through the interflow of supply and demand, the total aggregate matching is generated. At present, the matching problem in disabled labor market is mainly focused on the base layer, causing severe shrink of communicating quantity in communication layer. Due to the above reasons, the finally total amount matching is extremely small. To improve the employment situation, the macro policy should pay great attention to the role of the base layer, and then promote the infrastructure construction constantly.
\end{abstract}

\section{Keywords}

The Disabled Labor Market, Supply and Demand Matching, Two-Stage Matching Model, Macro-Control

\section{Research Background}

The disabled labor market is composed of labor supply and labor demand, the supply side refers to labor supply of the disabled, while the demand side refers to the employers' demand for the disabled. Due to the physical disabilities and low level of education, their enthusiasm to participate in the labor market and the degree of acceptance by the labor market are far lower than the healthy people. Supposing the employer is of perfect rationality, their willingness to hire people with disabilities will be very low, if any, they just want to fulfill social responsi- 
bility [1] [2].

At this stage, the basic undertaking of the disabled is still very weak. The government and the society are not authentically concerned about the labor market of the disabled. Besides, there is no independent accounting of the disabled labor market [3]. In addition, problems such as the lack of data management seriously restrict the research and control of the employment of the disabled [4].

This paper devotes itself to invoking a variety of social resources, as far as possible, under such social environment. We will try every feasible research methods, through multi-directional information gathering and analysis, to analyze the unbalance mechanism of the disabled labor market. Based on this, we combine with the relevant theories and the macroscopic measures of the general labor market, to put forward the optimization scheme of the disabled labor market.

\section{Research Status}

The problem of employment of the disabled is a complex problem all around the world. Each country is attempting various feasible institutions and measures. South Korea, Japan, Austria and other countries have implemented the employment security system for the disabled. However, different countries have different evaluation on different policies, and the prospective is discrepant. In many related researches of the employment of the disabled, it is relatively deep and scientific to learn the employment security system for the disabled, which benefited from the early study on establishing related database in some countries, who then obtain sufficient research resources [5] [6] [7]. Overall, most of the relevant literatures have mentioned the common employment assistance measures for the disabled, but the evaluations are rather conservative. In other words, currently, there are no very effective measures worldwide [8].

Unfortunately, almost no literatures describe the supply-demand relationship in the disabled labor market from the perspective of matching supply and demand. Some of the literatures have been aware of this view, however, they haven't done a further work. On the contrary, it is the essential part of this study.

\section{Theory on the Disabled Labor Market}

\subsection{New Definition of Terms}

In this paper, the concept of voluntary unemployment refers to the phenomenon of unemployment, that someone can achieve self-realization without employment. However, the traditional definition exists as the unemployment phenomenon that someone does not accept the current salary. This renewed definition has particularly scientific basis under the disabled labor market. From the following analysis, it can be seen that subjective factors play a leading role in the employment of disabled persons. That is to say, the decisive source, causing a great deal of unemployment among the disabled, is not the unwillingness, but the disabled think they are not competent for a job. Therefore, it won't be beneficial to reach social justice, when putting the disabled into the category of vo- 
luntary unemployment. Importantly, circumstances among these people must be taken into account, whether in theory researching or in policy setting.

\subsection{Research on the Disabled Labor Market}

First of all, we'd like to discuss the definition of the disabled labor market. Then, we will explore its decision mechanism from the perspective of supply and demand [9]. Finally, we plan to study the matching method and matching mechanism of supply and demand [10].

At present, the mainstream view is that the labor market is segmented. Nevertheless, there are a great many controversies about the specific segmentation boundary [11] [12]. Under the framework in this study, the labor market can be divided into the ordinary labor market and the disabled labor market. In terms of the labor supply, differentiations are shown as follows:

1) A huge difference in labor itself

The majority of people with disabilities receive education, from childhood, which is quite different from a healthy one, leading to a holistic lower level of education for the disabled. Furthermore, it causes significantly lower level of labor force than the ordinary one [13].

2) The different mechanisms of market participation

There have been specially preference policies for the disabled labor. For example, economic subsidies are adopted for enterprises which employ disabled persons [14]. Under such systems, the disabled labor market is not simply a perfectly competitive market, but an imperfect competition market with seller's power.

These special systems do not exist in the original labor market. In addition, this market is less affected by other external factors. For instance, the same level of production of labor and the same wage level of employers are basically perfectly competitive [15].

To sum up, it can be considered as separate between the disabled labor market and the original labor market. Therefore, this study is feasible under the framework of the disabled labor market [16]. However, the situations and theories of supply and demand in the original labor market will be very important reference.

\section{Two Stage Matching Model}

\subsection{Supply Side}

The unemployment of the disabled is determined by the capability of the labor force and the will of the disabled. Therefore, supposing that supply is a function of two variables, which include the capability factor and the psychological factor (Table 1). There are correlations between these two factors, through which an index system with two variables is established as follows:

1) Operational capability:

Occupational-basic capability refers to the skill level of the ordinary labor.

Occupational-professional capability refers to the skill level of the professional 
Table 1. Base layer of supply side.

\begin{tabular}{|c|c|}
\hline Operational capability & \\
\hline & Occupational-basic capability \\
\hline & $\begin{array}{l}\text { Occupational-professional capability } \\
\text { Occupational-capacity evaluation }\end{array}$ \\
\hline \multicolumn{2}{|l|}{ Psychological feature } \\
\hline & Anti-pressure capability \\
\hline & Recognition expected \\
\hline & Existence of discrimination \\
\hline & Disgust of discrimination \\
\hline
\end{tabular}

labor. Occupational-capacity evaluation refers to the evaluation of the operational capability by himself.

2) Psychological feature:

Psychological feature concerns about the psychological problems of the disabled, including anti-pressure capability, recognition expected, existence of discrimination and disgust of discrimination.

The two dimensions play a decisive role in the whole supply side (Table 2). Besides, the paper further examines another determinant-characteristic of employment demand. Employment-demand direction refers to the ideal industry and occupation.

Employment-environment and employment-treatment demand refer to the hardware and the software requirements to the employer. Job search channels usually restrict the free flowing of labor force, which is also the main cause of market friction. It is really rough for the disabled to obtain useful information, out of the deficiency of social resources. Hence, job search channels are likely to be a reasonably important cause of unemployment among the disabled.

\subsection{Demand Side}

As for demand side (Table 3), some factors directly determine the employers will not hire disabled workers. For example, industry characteristics determine that the construction industry is difficult to use the labor force lacking physical activity. In addition, corporate culture is also an important factor. For example, it is difficult for an employer who has a strong discrimination mentality to implement the decision of hiring disabled people. With the culturally dominant characteristic, an index system with two variables is established as follows [17].

In the decision-making mechanism of the employer, the base layer is relatively weak, while it is fully embodied in the communication layer, which mainly includes employee competence requirement, employee psychological requirement and employing characteristics (Table 4).

\subsection{Matching of Supply and Demand}

The purpose of this study is to improve the matching mechanism between supply and demand in the disabled labor market. First and foremost, the measurement 
Table 2. Communication layer of supply side.

\begin{tabular}{c}
\hline Characteristic of employment demand \\
\hline Employment-demand direction \\
Employment-environment demand \\
Employment-treatment demand \\
Job search channels \\
\hline
\end{tabular}

Table 3. Base layer of demand side.

\begin{tabular}{cc}
\hline Basic characteristics of the employers & \\
\hline Cultural characteristics & $\begin{array}{c}\text { Industry characteristics } \\
\text { Ownership characteristics } \\
\text { job characteristics }\end{array}$ \\
\hline & \\
\hline & Cultural tolerance \\
Discrimination degree \\
Environment friendly
\end{tabular}

Table 4. Communication layer of demand side.

\begin{tabular}{|c|c|}
\hline Employee competence requirement & \\
\hline & Education level \\
\hline & Vocational capability \\
\hline \multicolumn{2}{|l|}{ Employee psychological requirement } \\
\hline & Confidence degree \\
\hline & Compressive capacity \\
\hline & Regard evaluation Rationally \\
\hline \multicolumn{2}{|l|}{ Employing characteristics } \\
\hline & Employing status \\
\hline & Information distribution channel \\
\hline
\end{tabular}

index must be explicit. The aggregate Indicators describing the balance of supply and demand includes: demand scale and supply scale.

At the other extreme against aggregate matching, it is complete accordance in distribution. However, it is tough to use the same indicators when showing the distribution of two things. In addition, distribution is always in a running status, which is hard to predict.

Therefore, we need to find a balance between the matching aggregate and the specific distribution, which can reflect the matching degree of supply side and demand side and have a certain flexibility and operability. Combined with the above analysis framework, we establish the following analysis model (Figure 1) [18].

After the filtrating of base layer, supply and demand enter into communication layer. Then, passing through the matching action in communication layer, matching aggregate is finally formed. Because of the differences between the two 


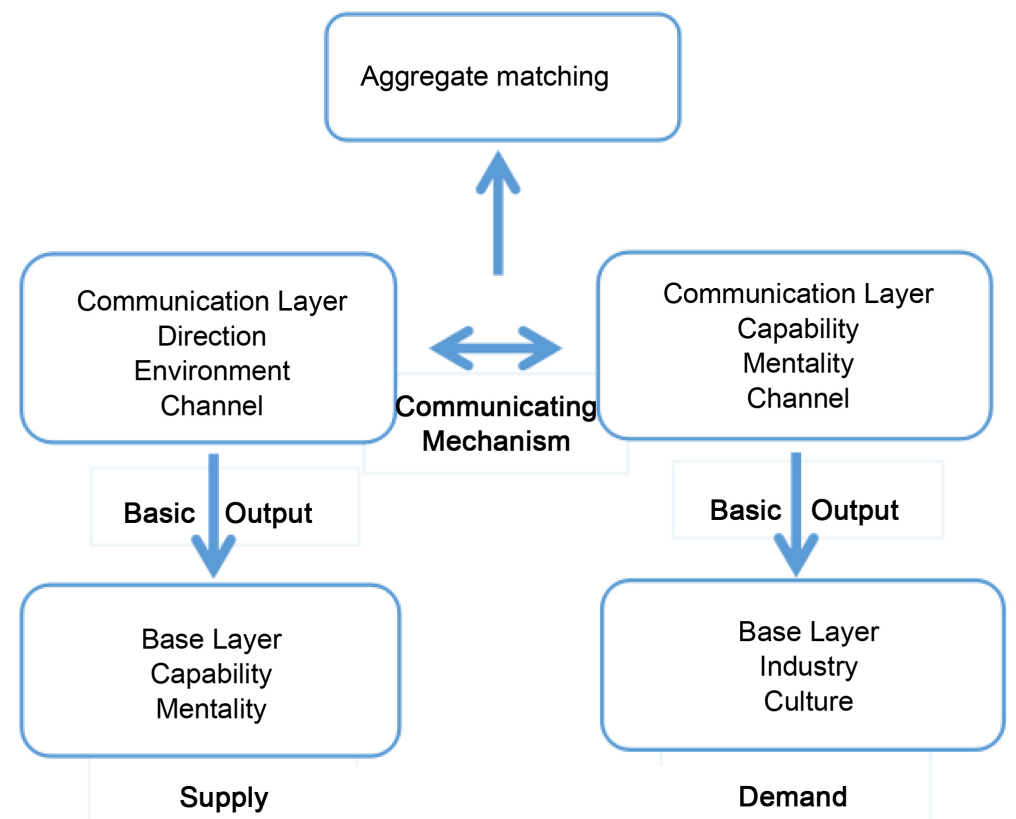

Figure 1. Basic analysis model.

sides in base layer, greater disparity was exposed in communication layer. From this perspective, it will be very difficult to reach a balance between supply and demand in disabled labor market.

\section{Macro-Control Measures}

\subsection{Laws and Regulations System}

Laws and regulations system mainly includes the safeguard clauses and the incentive clauses. The safeguard clauses are designed to eliminate the psychological pressure of the disabled and improve their social recognition, which is applied to base layer of supply [19]. The incentive clauses act on the output of base layer of the demand side, and its output in base layer is ascending through economic subsidy policies. Furthermore, the incentive clauses have the function of promoting communication, which can compensate the opportunity cost for employer from employing the disabled, and reduce communicating friction in the meantime [20].

Obviously, most countries have realized that it is very significant to encourage the supply and demand sides to participate in market matching. However, the effect of these two policies is not ideal.

First of all, the safeguard clauses are almost inefficient. Disabled people possess finite understanding of the legal system. Moreover, they can't afford high litigation costs to protect their rights and interests. In fact, the number of countries who use the safeguard clauses to protect the employment rights of persons with disabilities is quite few.

Secondly, the actual implementation of the incentive clauses is defective. The main source of income for incentive clauses is the employment security fund for the disabled. In practice, the actual use of security funds is not perfect, so it is 
not enough to achieve the established objectives.

\subsection{Auxiliary Employment Facilities}

Auxiliary employment facilities can be divided into the basic auxiliary facilities and the alternating auxiliary facilities. The basic auxiliary facilities are to help the disabled to integrate into society, under the guidance of professionals. Besides, the alternating auxiliary facilities directly train the employ ability of people with disabilities, and promote the interaction of supply and demand [21] [22] [23].

\subsection{Countermeasures and Suggestions}

1) Improve infrastructure construction.

Infrastructure is not an auxiliary facility convenient for people with disabilities, but the integrated record system for the disabled, which is an essential fundamental for further management and research [24]. In addition, it is necessary to improve the information system for disabled persons and the collectionmanagement system of employment security fund of the disabled. What's more, the effective design of the database may ensure the data consistency.

2) Improve base layer and the efficiency of the output of base layer.

The current problem in employment is mainly concentrated on base layer. For example, the social participation of the disabled is not active, and there are discriminations among the employing units. To solve the problem of employment of the disabled, we need to perfect the output of base layer as soon as possible.

Supply side: Increase the strength of civil rights education. First of all, charity is not a very good incentive, it will make people with disabilities think that their existence is a burden [25]. However, the education of civil rights is a completely different concept, which considers that the rights of the disabled are inherent, rather than kindness from other members of the society. Thus, we should strengthen the protection of the rights among persons with disabilities, in the mass media and education system.

Demand side: It is necessary to put a great use of the industry associations to promote the social significance of the employment of the disabled, and eliminate the discriminatory culture within the enterprises. Generally speaking, there has been a pervasive phenomenon that the authenticity and accuracy of financial statements are fairly unsubstantial in welfare enterprises. Therefore, it is necessary to establish solidly financial regulations that can reflect the financial situations of the welfare enterprises, through which the transparency and authenticity of financial information can be improved.

\section{References}

[1] Xie, E. (2011) Disability and Labor Market-Evidence from Chinese Urban Men. Management World, No. 4, 37-45.

[2] Lai, D.S., Liao, J. and Liu, W. (2008) Employment of Disabled People in China and Its Influencing Factors. Journal of Renmin University of China, 22, 10-15.

[3] Liang, B. (2005) An Investigation Report on the Development and Financing of 
Small and Medium Sized Enterprises in China. Journal of Financial Research, No. 5, 120-138.

[4] Chen, G., Guo, C. and Chen, X.M. (2014) The Design and Methods of the TwoTime National Sampling Survey for the Disabled. Population and Development, 20, 45-51.

[5] Zhao, M.M. (2012) A Comparative Study on the Employment Security of the Disabled in China and Japan. China Social Welfare, No. 10.

[6] Bing, L.Y. (2013) A Comparative Study on the Employment Status of Disabled People in China and America. Jiangsu Commercial Forum, No. 29, 277-278.

[7] Lechner, M. and Vazquez-Alvarez, R. (2004) The Effect of Disability on Labour Market Outcomes in Germany: Evidence from Matching. CEPR Discussion Papers, No. 967.

[8] Bell, D.N.F. and Heitmueller, A. (2005) The Disability Discrimination Act in the UK: Helping or Hindering Employment amongst the Disabled. IZA Discussion Paper, No. 1476.

[9] Wu, J.N. and Liu, J. (2007) Constructing the Performance Evaluation System of Financial Expenditure Based on Logical Model-Taking the Financial Expenditure of Agriculture as an Example. Journal of Zhongnan University of Economics and Law, No. 2, 69-74.

[10] Marie, O. and Castello, J.V. (2011) Measuring the (Income) Effect of Disability Insurance Generosity on Labour Market Participation. Journal of Public Economics, 96, 198-210.

[11] Yang, S.H. (2006) Some Thoughts on the Innovation Strategy of the Disabled Employment Rate. Scientific and Technical Information of Gansu, 35, 51.

[12] Chen, K., Osberg, L. and Phipps, S. (2015) Inter-Generational Effects of Disability Benefits: Evidence from Canadian Social Assistance Programs. Journal of Population Economics, 28, 873-910. https://doi.org/10.1007/s00148-015-0557-9

[13] Humer, B., Wuellrich, J.P. and Zweimüller, J. (2007) Integrating Severely Disabled Individuals into the Labour Market: The Austrian Case. IZA Discussion Papers, No. 2649.

[14] Malo, M.Á. and Pagán, R. (2014) Hiring Workers with Disabilities When a Quota Requirement Exists: The Relevance of Firm's Size. Disadvantaged Workers, Springer International Publishing, 49-63.

[15] Stone, C. and Stone, D.L. (2015) Factors Affecting Hiring Decisions about Veterans. Human Resource Management Review, 25, 68-79.

[16] Torre, L.V.D. and Fenger, M. (2014) Policy Innovations for Including Disabled People in the Labour Market: A Study of Innovative Practices of Dutch Sheltered Work Companies. International Social Security Review, 67, 67-84. https://doi.org/10.1111/issr.12038

[17] Qin, S.S. (2014) Factors Influencing the Employment of Disabled People and Employment Promotion Strategy. Journal of Ningxia Communist, No. 4, 49-53.

[18] Fan, N. (2010) Analysis on the Causes and Solutions of Employment Difficulties for the Disabled in China. Northwest University.

[19] Lalive, R., Wuellrich, J.P. and Zweimüller, J. (2009) Do Financial Incentives for Firms Promote Employment of Disabled Workers? A Regression Discontinuity Approach. CEPR Discussion Papers, No. DP7373.

[20] Yue, Y.Y. (2012) Analysis on the Problems, Causes and Countermeasures of the Employment Security for the Disabled in China. China Collective Economy, No. 30, 191-192. 
[21] Yue, Y.Y. (2013) Research on the Current Situation and Problems of Employment Security Fund for the Disabled in China. Labor Security World, No. 22.

[22] Xu, J. (2012) Problems and Suggestions on the Management of Employment Security Fond for the Disabled. Foreign Investment in China, No. 24, 325.

[23] Moore, T.J. (2015) The Employment Effects of Terminating Disability Benefits. Journal of Public Economics, 71, 70-71. https://doi.org/10.2139/ssrn.2547341

[24] Acemoglu, D. and Angrist, J.D. (2001) Consequences of Employment Protection. The Case of the Americans with Disabilities Act. Journal of Political Economy, 109, 915-957. https://doi.org/10.1086/322836

[25] Verick, S. (2004) Do Financial Incentives Promote the Employment of the Disabled. Social Science Electronic Publishing.

Submit or recommend next manuscript to SCIRP and we will provide best service for you:

Accepting pre-submission inquiries through Email, Facebook, LinkedIn, Twitter, etc. A wide selection of journals (inclusive of 9 subjects, more than 200 journals)

Providing 24-hour high-quality service

User-friendly online submission system

Fair and swift peer-review system

Efficient typesetting and proofreading procedure

Display of the result of downloads and visits, as well as the number of cited articles Maximum dissemination of your research work

Submit your manuscript at: http://papersubmission.scirp.org/

Or contact jhrss@scirp.org 